\title{
Peel Fluorescence as a Means to Identify Freeze-damaged Navel Oranges
}

\author{
David Obenland $^{1,4}$, Dennis Margosan ${ }^{1}$, Sue Collin², \\ James Sievert ${ }^{2}$, Kent Fjeld ${ }^{2}$, Mary Lu Arpaia ${ }^{2}$, James Thompson ${ }^{3}$, \\ and David Slaughter ${ }^{3}$
}

\begin{abstract}
AdDitionAl INDEX WORDs. Citrus sinensis, sensory, peel oil, black light
SUMMARY. The use of ultraviolet fluorescence to identify freeze-damaged navel oranges (Citrus sinensis) was evaluated using fruit harvested following a natural freeze that occurred in California in Jan. 2007. Navel oranges were harvested after the freeze from 14 sites that were previously determined to have a slight to moderate amount of freeze damage. The fruit were evaluated for the presence of small yellow spots characteristic of freeze damage that fluoresce when viewed under a ultraviolet$A(365 \mathrm{~nm})$ source and were then cut and rated using a method currently used by the California Department of Food and Agriculture (CDFA) to determine the presence of internal freeze damage. The percentage of freeze-damaged fruit in each lot as determined by the CDFA method ranged from $0 \%$ to $89 \%$. The accuracy of classifying fruit as freeze damaged in each lot by peel fluorescence averaged $44 \%$, with the fruit lots containing the greatest amount of freeze damage having the highest classification percentages. False-positives occurred at a lower rate than falsenegatives among the lots. Although some fading was evident, the fluorescence persisted and was readily visible for at least 9 weeks after the freeze event. Removal of fruit with ultraviolet peel fluorescence was ineffective in reducing the percentage of damaged fruit within the examined lots. In the second part of the test, eighteen lots of potentially freeze-damaged fruit were obtained from a packing house, immediately evaluated for freeze damage using ultraviolet light, and then after 4 weeks of storage, were evaluated again using the CDFA method. Fruit that had a slight to moderate degree of freeze damage were tasted and evaluated for sensory characteristics. Both methods of freeze damage detection were poorly related to the sensory characteristics.
\end{abstract}

$\mathrm{T}$ he marketability of navel oranges can be severely reduced by exposure to freezing conditions in the field. Ice crystals forming within the fruit damage the membranes of the juice sac cells and lead to enhanced water loss through the peel when thawed (Syvertsen, 1982). Over time, this water loss will cause the fruit to have a dry texture and to become unacceptable. In addition, freezing can cause a loss of flavor quality by initiating the accumulation of bitter limonoid compounds within the fruit (Manners et al., 2003).

This work was partially funded by a grant from the Citrus Research Board.

We thank Paul Neipp for his excellent assistance with this project.

${ }^{1}$ U.S. Department of Agriculture, Agricultural Research Service, 9611 South Riverbend Avenue, Parlier, CA 93648

${ }^{2}$ Kearney Agricultural Center, University of California, Parlier, CA 93648

${ }^{3}$ Biological and Agricultural Engineering, University of California, Davis, CA 95616

${ }^{4}$ Corresponding author. E-mail: david.obenland@usda. ars.gov.
The degree of freeze damage to the fruit of a particular orchard subjected to mild to moderate freezing conditions usually cannot be readily determined by the eye as navel oranges often do not show obvious injury to the peel surface following a freeze (Bartholemew et al., 1950). In California, regulations from the California Department of Food and Agriculture mandate that fruit from suspected freeze areas be cut and rated for internal symptoms of freeze damage following a freeze event (State of California, 2008). The CDFA method for determining if a particular lot of fruit can be legally packed and sold depends on visual inspection of cut fruit for symptoms of freeze damage, such as soaking of the segment walls and the presence of hesperidin crystals. Up to $15 \%$ of the fruit in a lot can be damaged and the lot can still be legally marketed. The subjectivity and difficulty in implementing the CDFA methodology for determining freeze damage makes it likely that damaged fruit sometimes enter the marketplace following a freeze. In addition, the destructive nature of the test means that only a sample of fruit can be tested, not each individual fruit. Two weeks or more after a freeze, the degree of internal dehydration may reach a point where separation of damaged fruit can be achieved on the packing line by using the specific gravity differences between damaged and undamaged fruit (Miller et al., 2006). This means of freeze damage detection cannot be done immediately after a freeze, and is problematic when there are fruit of differing shapes and peel thicknesses within individual lots of fruit being examined.

Recently, it was reported that small (1-2 $\mathrm{mm})$ bright yellow fluorescing spots are visible on the peel surface of freeze-damaged navel oranges when viewed under a longwave ultraviolet source (Slaughter et al., 2008). It was proposed that the spots are due to the rupture of oil glands during the freeze and subsequent thaw, and the migration of tangeritin, a fluorescing component of the oil, closer to the peel surface, allowing it to be visible under ultraviolet illumination. We have observed that other types of injury that can cause oil release, such as oleocellosis or mechanical abrasions, also fluoresce but produce a distinctly different appearance from the very small dot pattern associated with freeze damage. Slaughter et al. (2008) used fruit that had been frozen using laboratory-simulated freezes (due to the unavailability of naturally frozen fruit) to evaluate the use of peel fluorescence to detect freeze-damaged navel oranges. Although the tests showed peel fluorescence to be a

\begin{tabular}{llll}
\hline $\begin{array}{l}\text { Units } \\
\text { To convert U.S. to SI, } \\
\text { multiply by }\end{array}$ & U.S. unit & SI unit & $\begin{array}{l}\text { To convert SI to U.S., } \\
\text { multiply by }\end{array}$ \\
\hline 29.5735 & $\mathrm{fl} \mathrm{oz}$ & $\mathrm{mL}$ & 0.0338 \\
2.54 & inch $(\mathrm{es})$ & $\mathrm{cm}$ & 0.3937 \\
25.4 & inch $(\mathrm{es})$ & $\mathrm{mm}$ & 0.0394 \\
1 & ppm & $\mu \mathrm{L}^{-1}$ & 1 \\
$\left({ }^{\circ} \mathrm{F}-32\right) \div 1.8$ & ${ }^{\circ} \mathrm{F}$ & ${ }^{\circ} \mathrm{C}$ & $\left(1.8 \times{ }^{\circ} \mathrm{C}\right)+32$
\end{tabular}


rapid, nondestructive method of classifying navel oranges as damaged or not damaged and well suited for use as an automated sorting method on the packing line, it was recognized that additional experimentation using naturally frozen navel oranges would be necessary to fully evaluate the peel fluorescence methodology. The 2007 freeze provided the opportunity to test naturally frozen fruit when cold weather damaged a significant portion of the California navel orange crop. This research documents the relationship between CDFA-scoreable freeze damage, peel ultraviolet fluorescence, and sensory quality of field harvested navel oranges following the Jan. 2007 California freeze.

\section{Materials and methods}

FIELD FREEZE DAMAGE SURVEYS. On 12-16 Jan. 2007, freezing conditions occurred in California that caused extensive damage to the citrus crops. Following the freeze, 14 locations were identified within Fresno and Tulare counties that potentially contained freeze-damaged navel oranges for use in evaluating the peel fluorescence freeze damage detection method. Selection of the locations was accomplished by randomly cutting fruit in the field and looking for early signs of freeze damage, such as hesperidin crystals, ruptured juice sacs, or a water-soaked appearance internally in the fruit. Severely damaged groves were avoided as this degree of damage would be easy to accurately ascertain without the need for new methodology. The fruit were harvested for the first time immediately after freezing conditions or from 14 to $35 \mathrm{~d}$ following the end of freezing, depending on the location (see Table 1). Locations 1 to 4 and 8 were only harvested a single time, while the remaining locations were harvested every 3 weeks either a total of two times (locations 9, 13, and 14) or a total of three times (locations 5 to 7 and 10 to 12 ) to determine the degree of persistence of the peel fluorescence. Fifty fruit (size 55-88; 7.5$8.5 \mathrm{~cm}$ in diameter) were taken from each site at each harvest date, taking care not to pick fruit that had obvious defects such as ice marking (small sunken spots on the peel surface), sunburn, or evidence of thrip feeding. Following harvest, the fruit were transported to the Kearney Agricultural Center (Parlier, CA) and were further sorted to remove any remaining defective fruit, leaving 33 to 50 fruit per site for evaluation.

After numbering each fruit, the fruit were moved into a dark room and were individually rated under ultraviolet illumination $(365 \mathrm{~nm}$, Blak$\mathrm{Ray}^{\circledR}$ model B-100AP; UVP, Upland, $\mathrm{CA}$ ) using a five-point scale based on the number of small, yellow fluorescent spots present on the peel surface (Fig. 1). These spots had been previously shown to be characteristic of freeze damage and are different from other types of fluorescing marks, such those due to mechanical damage that are observed on the peel surface (Slaughter et al., 2008). The scale ranged from 1 (no spots) to 5 (greater than 20 spots). Following storage overnight at $20^{\circ} \mathrm{C}$, the same fruit were cut and evaluated for freeze damage using the official method mandated by the CDFA (State of California, 2008). All evaluators received training from county inspectors experienced in the evaluation of freeze-damaged fruit. Soaking of the segment walls and the presence of hesperidin crystals were the primary symptoms used to determine whether a fruit was freeze damaged. Either of these symptoms had to be present along the entire length of both sides of two segments for a fruit to be declared damaged according to the CDFA method (CDFA-damaged) and unmarketable. We also recorded when fruit had lesser amounts of freeze damage that were under the threshold needed to declare the fruit damaged by the CDFA method. Individual fruit were tracked so that the amount of freeze damage could be related to the peel fluorescence rating previously given to that fruit.

Taste Panel evaluation OF COMMERCIALLY PICKED FRUIT. Navel oranges were obtained six times $(7$ Feb., 13 Feb., 21 Feb., 7 Mar., 21 Mar., and 4 Apr.) over a period of 8 weeks from field bins in a commercial packing house beginning 3 weeks after the end of the freeze event. The delay in obtaining the fruit was necessary to ensure that we would be obtaining navel oranges that had been exposed to the freezing conditions and not fruit that had been picked before the freeze. Three separate lots, each lot representing a different grower, were obtained on each sampling date,

Table 1. Comparison of the percentage of navel oranges ${ }^{z}$ classified as freeze-damaged by the California Department of Food and Agriculture (CDFA) method or navel oranges having any internal freeze damage before and after sorting for external peel fluorescence using ultraviolet light at $365 \mathrm{~nm}$ for 14 separate locations.

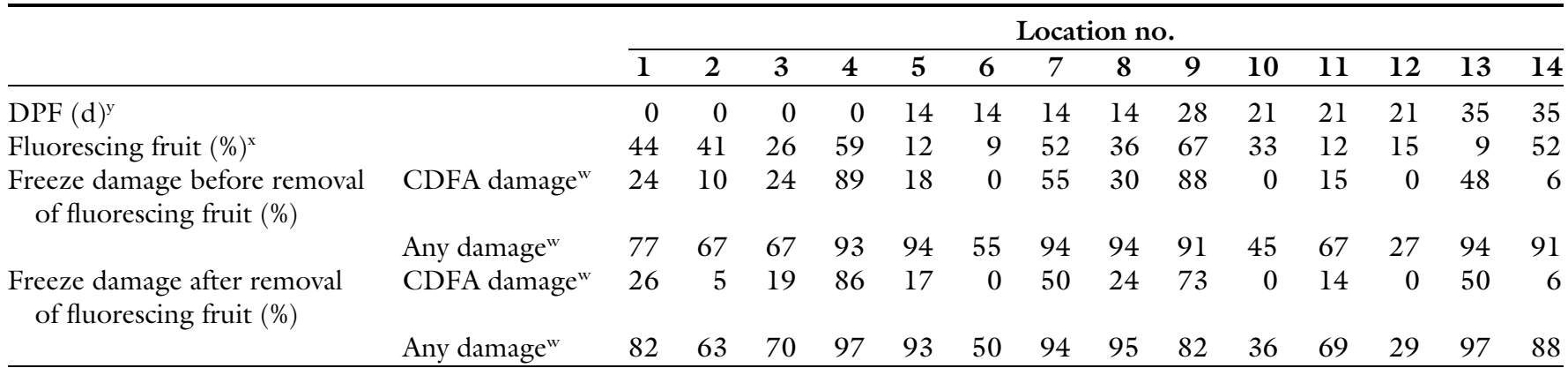

${ }^{2}$ Fruit were harvested (33-50 fruit/location evaluated) from 14 locations immediately after freezing conditions $(0 \mathrm{~d})$ or 14 to $35 \mathrm{~d}$ following the end of freezing. Data are from the initial harvest of each location.

${ }^{y}$ Days past end of freezing conditions.

xercentage of fruit with fluorescence on the peel surface (threshold rating $\geq 2$ for all locations except location 5 where the threshold was $\geq 3$ ) characteristic of freeze damage. "Percentage of freeze-damaged fruit before and after removing fruit that were above the ultraviolet fluorescence threshold rating $(\geq 2$ for all locations except location 5 where the threshold was $\geq 3$ ). Fruit were classified as freeze-damaged using the CDFA rating scheme (CDFA damage) or were rated as having any type of freeze damage (Any damage). Ratings for the CDFA were performed using segment evaluation as outlined in State of California (2008). 


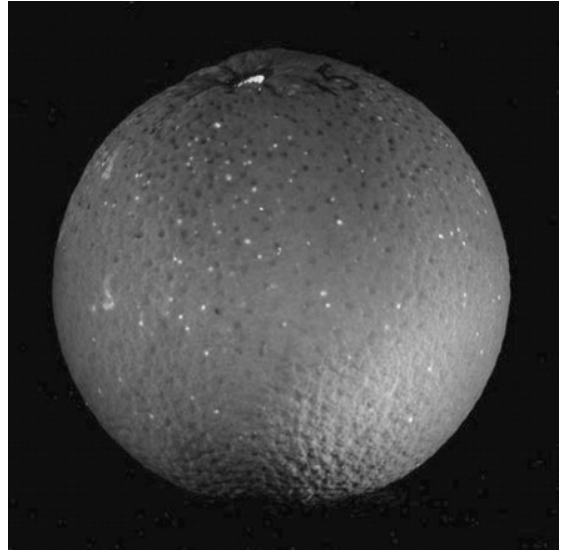

Fig. 1. Typical small yellow fluorescent spots visible under ultraviolet light on the peel surface of a navel orange following freezing and thawing.

with different growers being used for each date. A total of 175 size 72 fruit $(8 \mathrm{~cm}$ in diameter) were randomly selected for each lot from multiple field bins, taking care to select fruit free of ice marking, flat sides, sunburn, thrip marks, and other obvious surface defects. Following selection at the packing house, the fruit were transported to the Kearney Agricultural Center, sorted to remove any remaining defective fruit, numbered sequentially, and evaluated for peel fluorescence. The following day the fruit were washed and waxed with Sta-Fresh ${ }^{\circledR} 2210 \quad$ (FMC, Philadelphia) with $2000 \mu \mathrm{L} \cdot \mathrm{L}^{-1}$ imazalil, using the packing line at the University of California Lindcove Research and Extension Center in Exeter, CA (45 miles from the Kearney Agricultural Center). The fruit were then returned to the Kearney Agricultural Center where they were stored for 3 weeks at $5{ }^{\circ} \mathrm{C}$, followed by $4 \mathrm{~d}$ at $13{ }^{\circ} \mathrm{C}$ and $3 \mathrm{~d}$ at $20^{\circ} \mathrm{C}$ to simulate a period of storage and marketing. Humidity during storage was maintained between $90 \%$ and $95 \%$ relative humidity.

Following storage, fruit for taste panel evaluation were each cut into six equal latitudinal slices using a sectionizer (Sunkist, Ontario, CA), and the four innermost slices were used for tasting. Before tasting, the two innermost slices were examined for freeze damage-induced drying, and the percentage of the surface area with drying was recorded for each fruit. This evaluation was equivalent to the CDFA transverse cut rating for freeze damage as outlined in the CDFA regulations (State of California, 2008). Fruit with severe drying would have been impractical to taste, therefore only fruit with less than $20 \%$ of the surface of the inner slices showing freeze damage were used for tasting. This corresponded to slight or moderate freeze damage that would have passed CDFA grade standards. When preparing the samples for tasting, the central core of the slices was removed using a \#8 (0.5inch diameter) cork borer and the peel was removed by cutting a 1.75inch diameter circle from the center of the slice using a leather circle cutting tool. The resulting sample was placed into a $\mathrm{l}-\mathrm{fl}$ oz soufflé cup for presentation to the panelists within 2 to $4 \mathrm{~h}$ of cutting. Before presentation, the fruit were kept at 20 ${ }^{\circ} \mathrm{C}$. Each panelist received eight samples prepared in this manner in each tasting session. The sample presentation area consisted of individual, three-sided booths with small doors through which the samples were given to the panelists. The panelists, generally 15 to 20 individuals per test, were very familiar with tasting citrus and could be considered as experienced. A brief training session outlining the procedures to be followed was provided to all panelists. Samples were evaluated using the nine-point hedonic scale where $9=$ like extremely, $5=$ neither like nor dislike, and $\mathrm{l}=$ dislike extremely. The intensity of off-flavor, bitterness, juiciness, and fresh citrus flavor was scored using $150-\mathrm{mm}$ line scales. With these line scales, a single mark was placed by the panelist upon the scale length, the position of the line indicating the perceived intensity of the sensory parameter. Distilled water was used to cleanse the palate between samples. Each navel orange was tasted by four panelists. Tasting for each week was conducted over a $3-d$ period, with one grower lot being assessed each day.

A two-by-two contingency table analysis with the right-sided, Fisher's exact test was used to determine if the number of freeze-damaged fruit following selection using ultraviolet fluorescence was statistically significant from the number of fruit within each lot before selection. Data were subjected to a one-way analysis of variance within each lot to determine if ultraviolet peel fluorescence ratings changed over time for the field survey portion of the experiment. Mean values within each lot were compared using Tukey's test to determine statistical differences between means. Kendall's tau-b correlation coefficients were calculated using mean values from each lot to determine the relationships between ultraviolet ratings, freeze damage, and sensory scores in the taste panel portion of the test.

\section{Results}

Field FREEZE DAMAGE SURVEY. Each of the 14 locations that were believed to have been freeze damaged had fruit with the ultraviolet fluorescence characteristic of freeze-damaged fruit (Table 1). The percentage of fruit with this type of fluorescence ranged from $9 \%$ to $67 \%$. Ratings of these same fruit for freeze damage by using the CDFA method also indicated that a wide range of damage was present in the various locations (Table 1). This enabled a comparison of the peel fluorescence and CDFA methods with lightly and heavily damaged fruit. During evaluation of the fruit, it was noted that there was often freeze-related damage that was present, such as a soaked appearance of the segment walls, that did not reach the threshold required to designate the fruit as damaged according to the CDFA method. This lesser type of damage was also noted, and fruit that were damaged to this degree grouped with CDFA-damaged fruit to make a separate category labeled "any damage" in Table 1. This category contained all freeze-damaged fruit, no mater how slight the damage.

Testing the effectiveness of the peel fluorescence method in detecting freeze-damaged fruit was accomplished by noting the change in percentage of CDFA- or "any damage" fruit following removal from the lot of fruit with peel fluorescence characteristic of freeze damage (Table 1). For each lot, the ultraviolet peel fluorescence rating used to designate damage was used that minimized the percentage of CDFA damage for that lot. In all but the case of location 5 where the fluorescence rating cutoff for selection was $\geq 3$, selecting fruit with any fluorescence at all (rating $\geq 2$ ) was the most effective means of removing damaged fruit from the lot.

Sorting out fruit with peel fluorescence did not decrease the percentages of CDFA- or "any damage" to a 
statistically significant degree $(P \leq$ $0.05)$ in any of the lots from the 14 locations. Although it varied by location, overall, only $44 \%$ and $35 \%$ of the CDFA- and "any damage" fruit, respectively, were correctly classified by peel fluorescence (data not shown). These classification rates tended to be higher for locations with greater percentages of ultraviolet fluorescence present, even though they never exceeded $72 \%$. Undamaged fruit were classified at higher percentages, averaging $72 \%$ and $66 \%$ for the CDFA and "any damage" scoring systems, respectively (data not shown).

It had been previously observed in our laboratory that peel fluorescence could be seen on artificially frozen fruit stored at $5{ }^{\circ} \mathrm{C}$ for many weeks following a freeze treatment. As it was of interest how long peel fluorescence would persist under field conditions with fruit remaining on the trees, fruit were harvested from affected groves at 3-week intervals and were rated under ultraviolet light (data not shown). Locations 5 to 14 , with the exception of location 8, which was only sampled a single time, were all harvested at least two times.
Although it was noted that the ultraviolet fluorescing spots became more diffuse and dimmer over time, the spots could still be readily seen at the end of the rating period. In only two of the nine locations were there statistically significant declines in the ultraviolet peel fluorescence rating as a result of the passage of time, indicating that the fluorescence tended to be very persistent, even after 9 weeks following the freeze.

SENSORY EVALUATION OF COMMERCIALLY HARVESTED FRUIT. Because the CDFA method, and segment cutting especially, is a subjective and error-prone means of freeze damage and fruit quality evaluation, it makes a rather poor basis for evaluating the success of a new fruit evaluation method. As taste is a critical measure of fruit quality that is known to also be negatively affected by freezing (Manners et al., 2003), it was decided to address this problem by assessing taste in addition to measurements of peel fluorescence and CDFA damage. Because it was not feasible to taste fruit with severe drying, fruit with more than $20 \%$ drying, as judged by a longitudinal cut through the center of the fruit, were excluded from tasting. Table 2 presents results from these evaluations performed on 18 lots of commercially harvested fruit. The mean percentages of CDFA freeze damage in the individual fruit within the lot after removal of the severely damaged fruit ranged from $0 \%$ to $12.5 \%$. Peel ultraviolet fluorescence ratings were unrelated to any of the sensory parameters (Table 3 ). Measurements of the percentage of CDFA freeze damage were significantly related to the hedonic score and juiciness, but the relationship was not a strong one as evidenced by the low correlation coefficients for these two sensory characteristics.

\section{Discussion}

Fruit lots that had the highest levels of internal freeze damage generally had large amounts of fluorescence visible under ultraviolet illumination, and fruit in these lots tended to be more accurately classified as being damaged than in lots with lesser damage. However, even in the best case (location 9), there was only a reduction of $15 \%$ in CDFA damage as a result of sorting out fluorescing fruit

Table 2. Freeze damage in commercially harvested navel orange lots ${ }^{\mathrm{z}}$ as evaluated by a California Department of Food and Agriculture (CDFA) cutting protocol and the associated peel fluorescence and sensory parameters for each lot.

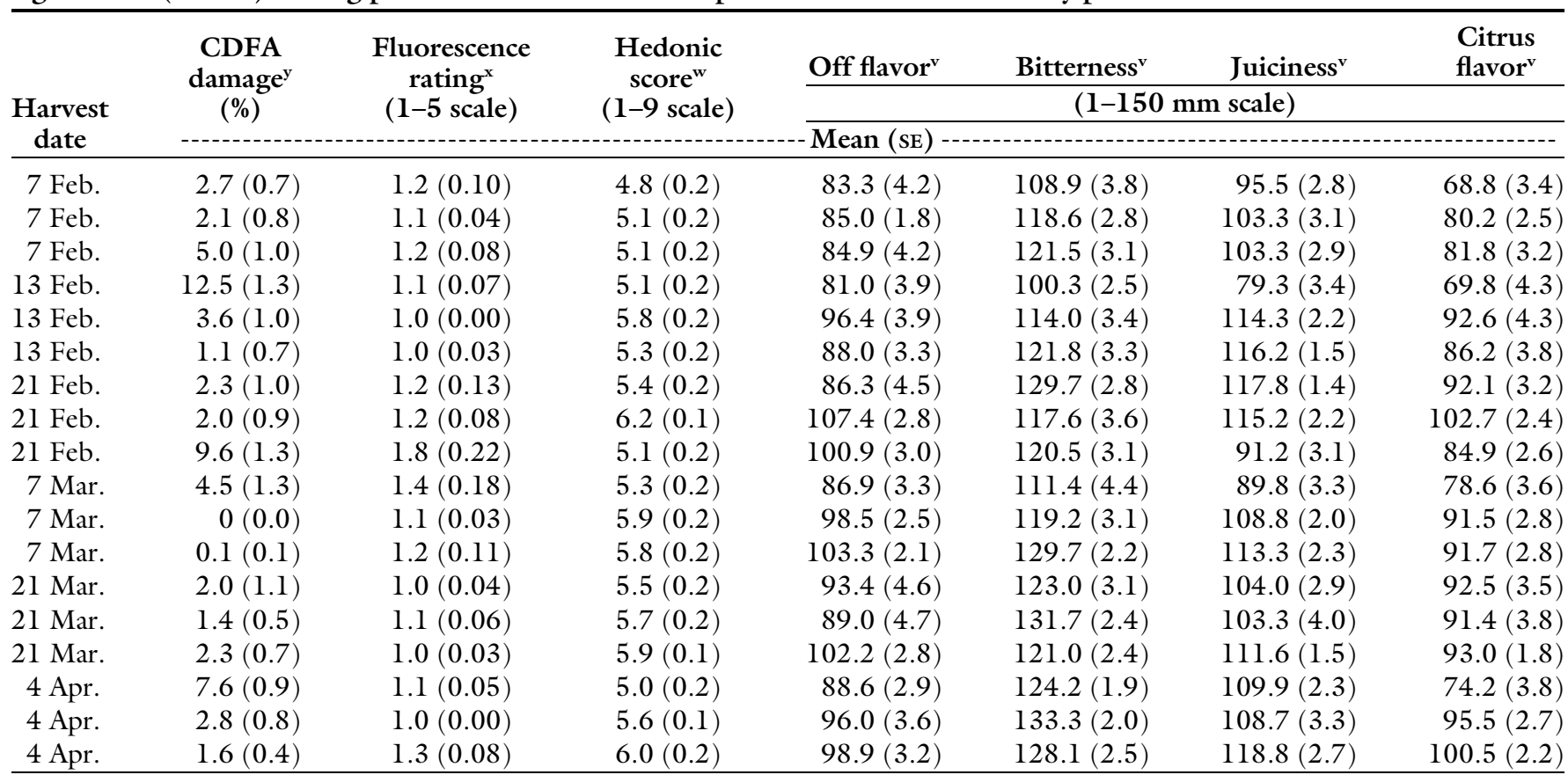

${ }^{2}$ Fruit were evaluated for peel fluorescence using ultraviolet light within a day of obtaining the fruit, and for freeze damage and sensory attributes after 4 weeks of storage. Between 23 and 40 fruit were evaluated within each of the 18 lots.

${ }^{y}$ Mean percentage of freeze damage in each lot as determined by a transverse cut of each fruit and estimation of the percentage of the cut area with drying. This damage evaluation was done as outlined in the CDFA freeze evaluation methods (State of California, 2008)

${ }^{x}$ Mean rating of peel fluorescence ranging from 1 (no fluorescent spots) to 5 (more than 20 fluorescent spots).

"Hedonic score ranged from 1 to 9 where $1=$ extremely dislike, $5=$ neither like or dislike, and $9=$ extremely like.

"For off-flavor and bitterness, a higher number indicates less, and for juiciness and citrus flavor, a higher number indicates more of that attribute. 
Table 3. Kendall's tau-b correlation coefficients between freeze damage as determined by California Department of Food and Agriculture (CDFA) evaluation methods and ratings for peel fluorescence with sensory characteristics ${ }^{\mathrm{z}}$ of commercially harvested navel oranges.

\begin{tabular}{lccccc}
\hline & $\begin{array}{c}\text { Hedonic } \\
\text { score }\end{array}$ & Off flavor & Bitterness & Juiciness & $\begin{array}{c}\text { Citrus } \\
\text { flavor }\end{array}$ \\
\hline Percentage of CDFA damage $^{\mathrm{y}}$ & $-0.42^{*}$ & -0.26 & -0.28 & $-0.38^{*}$ & -0.28 \\
Fluorescence rating $^{\mathrm{x}}$ & -0.12 & -0.01 & -0.09 & -0.16 & -0.20 \\
\hline
\end{tabular}

${ }^{\mathrm{z}}$ Higher ratings for off-flavor and bitterness indicated a lesser amount of that characteristic. Correlations were conducted using mean values for each of the 18 lots of navel oranges. An asterisk indicates statistical significance at 0.05 or below.

yercentage of freeze damage in individual fruit as judged by the CDFA transverse cut method (State of California, 2008). ${ }^{x}$ Ratings of peel fluorescence taken under ultraviolet light before storage.

from the lot (Table 1$)$. In locations with lesser amounts of damage, the fluorescing areas were few and it was sometimes difficult to make a decision regarding the status of the fruit. The greater difficulty in classifying fruit with low levels of freeze damage as observed in this study was also noted by Slaughter et al. (2008), who stated that the peel fluorescence method may be best suited for identifying moderately to severely frozen fruit. While the overall classification accuracy for fruit judged to be undamaged (marketable) by the CDFA method was similar in this study $(72 \%)$ to the values obtained by Slaughter et al. (2008), our classification accuracy for CDFA-damaged fruit was generally much less, which made it impossible for the peel fluorescence method to reduce the percentage of freezedamaged fruit in most of the locations. The difference in classification accuracy likely reflects the lesser degree of peel damage in most of the lots of naturally frozen fruit compared with fruit frozen in the laboratory in the previous work. The fact that peel damage appears to occur secondarily to internal damage (Bartholemew et al., 1950) may limit the sensitivity of the method and hamper its use as an inspection tool to replace the CDFA method. It has been our experience, however, that fruit with lesser amounts of damage are also the most difficult to categorize using the CDFA method as well, meaning that the peel fluorescence method is being compared with a method that in itself is likely not particularly accurate.

Temperature recordings taken in regions near to the groves sampled during the period of the freeze indicated that temperatures as low as those used in the prior laboratory experimentation $\left(-7^{\circ} \mathrm{C}\right.$, with durations of $4 \mathrm{~h}$ or more) were reached in some areas, although we do not know the exact temperatures and durations of the exposure experienced by the individual fruit sampled given the unplanned nature of the freeze. Rates of freezing and thawing that occurred during the natural freeze are other potential points of difference from the laboratory experimentation because that work had used freezing and thawing treatments at constant, rather than ramped, temperatures that occur naturally. Preliminary experimentation in our laboratory on the effect of thaw rate on the expression of peel fluorescence, however, found there to be no difference due to thaw rate (data not shown). The impact of multiple freeze and thaw cycles that occurred during the 2007 freeze also makes it difficult to directly compare these results to previous experimentation in the laboratory. A better understanding of the factors that influence peel damage and the subsequent release of oil into the surrounding tissues is needed to be able to better predict the effectiveness of the peel fluorescence method in detecting flesh damage following future natural freezes.

Peel fluorescence was not predictive of how well sensory panelists liked eating the fruit as estimated by the hedonic score (Table 3 ). As in the first part of the experiment, the amount of ultraviolet peel fluorescence present was often quite low and made classification of freeze damage by this method difficult. It was also obvious that hedonic score and other sensory parameters were not very responsive to differences in the range of freeze damage (slight to moderate). This was not due to differences among the lots for soluble solids concentration (SSC) or titratable acidity (TA) obscuring the effects of freeze on flavor, as the SSC:TA ratio was high and fairly similar for most of the lots (data not shown). One factor involved may have been the absence of a strong development of bitterness that is often associated with freeze-damaged fruit (Manners et al., 2003). The overall high ratings for bitterness indicated that there was very little bitterness in the fruit lots tasted. This may have been because the freeze occurred when the substrates needed for the production of bitter compounds may have been at low levels (Maier and Margileth, 1969). It is possible that under other circumstances, such as a different timing of the freeze event or in a different year, that there would have been a closer relationship between eating quality and cutting and peel fluorescence methods of freeze damage evaluation.

Although the information is anecdotal, the peel fluorescence method was reported to have been used by a number of packinghouses in California following the 2007 freeze with reports of success in removing freeze-damaged fruit to enable lots of fruit to pass the legal allowance for freeze-damaged fruit. Use of the peel fluorescence method was easily done in the packinghouses because they already possessed black light rooms to detect decayed fruit that, like freeze-damaged fruit, also fluoresce under ultraviolet illumination. Decay, though, appears as large fluorescing areas on the peel, distinct from the small spots present on freezedamaged fruit. Little or nothing extra was needed for the detection of frozen fruit except additional employee training and perhaps some small modification of the setup. It is possible that the frozen fruit present in the fruit lots evaluated by the packinghouses fluoresced more strongly and were easier to distinguish from nonfrozen fruit than those examined in this experiment. This could have been due to a greater degree of peel damage from the manner in which the fruit in that location froze and thawed or due to differences in peel morphology that allowed the fluorescing oil components to be more easily released. Additional research is needed to evaluate these possibilities.

\section{Literature cited}

Bartholemew, E.T., W.B. Sinclair, and R.P. Horspool. 1950. Freeze injury and subsequent seasonal changes in Valencia oranges and grapefruit. California Agr. Expt. Sta. Bul. 719:1-47. 


\section{Research Reports}

Maier, V.P. and D.A. Margileth. 1969. Limonoic acid A-ring lactone, a new limonin derivative in citrus. Phytochemistry 8:243-248.

Manners, G.D., A.P. Breksa, III, T.K. Schoch, and M.B. Hidalgo. 2003. Analysis of bitter limonoids in citrus juices by atmospheric pressure chemical ionization and electrospray ionization liquid chromatography-mass spectrometry. J. Agr. Food Chem. 51:3709-3714.

Miller, W.M., W.F. Wardowski, and W. Grierson. 2006. Separation and grading of freeze-damaged fruit, p. 299-306. In: W.F. Wardowski, W.M. Miller, D.J. Hall, and W. Grierson (eds.). Fresh citrus fruits. Florida Science Source, Longboat Key, FL.

Slaughter, D.C., D.M. Obenland, J.F. Thompson, M.L. Arpaia, and D.A. Margosan. 2008. Non-destructive freeze damage detection in oranges using machine vision and ultraviolet fluorescence. Postharvest Biol. Technol. 48:341-346.

State of California. 2008. California Code of Regulations, Title 3. Food and Agriculture, Division 3. Economics, Chapter 1. Fruit and vegetable standardization, Subchapter 4. Fresh fruits, nuts and vegetables, Article 22. Citrus, Code 1430.40.21 Feb. 2008. <http://weblinks.westlaw.com/Find/ Default.wl?:DB=CA\%2DADC\%2DTOC $\% 3$ BRVADCCATOC\&DocName $=3$ CAADCS $1430 \% 2 \mathrm{E} 40 \&$ Find Type $=\mathrm{W} \& \mathrm{AP}=\& \mathrm{fn}=$ top\&rs=WEBL9.01 \& ifm $=$ NotSet\&vr= 2.0\&spa $=$ CCR $-1000 \&$ trailtype $=26 \& C n t=$ Document $>$.

Syvertsen, J.P. 1982. Dehydration of freeze-damaged oranges. HortScience 17:803-804. 